\title{
Ultrasound-guided femoral and sciatic nerve blocks combined with sedoanalgesia versus spinal anesthesia in total knee arthroplasty
}

\author{
Akcan Akkaya ${ }^{1}$, Umit Yasar Tekelioglu ${ }^{1}$, Abdullah Demirhan ${ }^{1}$, Kutay Engin Ozturan ${ }^{2}$, Hakan Bayir ${ }^{1}$, \\ Hasan Kocoglu ${ }^{1}$ and Murat Bilgi ${ }^{1}$
}

${ }^{1}$ Department of Anesthesiology and Reanimation, ${ }^{2}$ Department of Orthopaedic Surgery and Traumatology, Abant Izzet Baysal University Medical School, Bolu, Turkey

Background: Although regional anesthesia is the first choice for patients undergoing total knee arthroplasty (TKA), it may not be effective and the risk of complications is greater in patients who are obese or who have spinal deformities. We compared the success of ultrasound-guided femoral and sciatic nerve blocks with sedoanalgesia versus spinal anesthesia in unilateral TKA patients in whom spinal anesthesia was difficult.

Methods: We enrolled 30 patients; 15 for whom spinal anesthesia was expected to be difficult were classified as the block group, and 15 received spinal anesthesia. Regional anesthesia was achieved with bupivacaine $62.5 \mathrm{mg}$ and prilocaine 250 $\mathrm{mg}$ to the sciatic nerve, and bupivacaine $37.5 \mathrm{mg}$ and prilocaine $150 \mathrm{mg}$ to the femoral nerve. Bupivacaine $20 \mathrm{mg}$ was administered to induce spinal anesthesia. Hemodynamic parameters, pain and sedation scores, and surgical and patient satisfaction were compared.

Results: A sufficient block could not be obtained in three patients in the block group. The arterial pressure was significantly lower in the spinal group $(\mathrm{P}<0.001)$, and the incidence of nausea was higher $(\mathrm{P}=0.017)$ in this group. Saturation and patient satisfaction were lower in the block group $(\mathrm{P}<0.028)$, while the numerical pain score $(\mathrm{P}<0.046)$ and the Ramsay sedation score were higher $(\mathrm{P}=0.007)$.

Conclusions: Ultrasound-guided sciatic and femoral nerve blocks combined with sedoanalgesia were an alternative anesthesia method in selected TKA patients. (Korean J Anesthesiol 2014; 67: 90-95)

Key Words: Arthroplasty, Femoral nerve, Knee, Nerve block, Sciatic nerve, Ultrasonography.

Received: October 2, 2013. Revised: 1st, December 16, 2013; 2nd, January 29, 2014. Accepted: February 21, 2014.

Corresponding author: Akcan Akkaya, M.D., Department of Anesthesiology and Reanimation, Abant İzzet Baysal University Medical School, 14280 Golkoy, Bolu, Turkey. Tel: 90-3742534656, Fax: 90-3742534615, E-mail: akcanakkaya@hotmail.com

(a) This is an open-access article distributed under the terms of the Creative Commons Attribution Non-Commercial License (http:// creativecommons.org/licenses/by-nc/3.0/), which permits unrestricted non-commercial use, distribution, and reproduction in any medium, provided the original work is properly cited. 


\section{Introduction}

Total-knee joint arthroplasty (TKA) is more common than ever due to increased life expectancy and an increased incidence of obesity, especially in elderly females [1]. These patients are also poor candidates for general anesthesia because they have diseases such as diabetes and hypertension and a decreased systemic functional reserve [2]. Anatomical deformities in the aforementioned patients also reduce the success of regional anesthesia [3]. Sudden hemodynamic changes during spinal anesthesia pose an additional risk due to the presence of accompanying diseases and previous neurological disorders [2]. As quadruple nerve blocks of the lower extremities require high-dose local anesthetics, the risk of systemic side effects is increased [4]. Nevertheless, these blocks are preferred for analgesia [5]. The use of ultrasonography (USG) during peripheral blocks increases their effectiveness and decreases the amount of anesthetic required [6]. Several studies have evaluated peripheral nerve blocks for lower extremity surgeries [7,8] and compared them with spinal anesthesia $[9,10]$. This study examined specifically whether a peripheral nerve block can be used in ASA II/III, TKA patients at relatively high risk for general anesthesia and who lack waist anatomy suitable for regional anesthesia. Therefore, we examined the effectiveness of combined sciatic and femoral blocks under sedoanalgesia in patients undergoing TKA using an appropriate dose of local anesthetic with ultrasonographic guidance.

\section{Materials and Methods}

After receiving approval from the Abant İzzet Baysal University Clinical Studies Ethics Committee (Study Number 2011/60), we enrolled 30 patients of American Society of Anesthesiologists (ASA) risk group II/III who were scheduled for unilateral TKA. Informed consent was obtained from all patients preoperatively. The exclusion criteria were bilateral surgery, anesthesia risk outside ASA II/III, and patient refusal.

Routine intraoperative monitoring was used in all cases, including electrocardiography, oxygen saturation $\left(\mathrm{SpO}_{2}\right)$, and non-invasive blood pressure measurements. Intravenous (IV) access was obtained. The patients were given oxygen via a facemask at 2-3 L/ min. The patients were divided into two groups: the block group (Group B) and the spinal anesthesia group (Group S). Group B included patients with waist anatomy that could cause difficulty with regional anesthesia. Selection was based on whether one of the following conditions was present: non-visible and nonpalpable spinal processes, no palpable space between the spinal eminences, or flexion constraints at the L3-5 vertebral levels (absence of convexity). A single senior anesthesiologist performed the group selections for all patients. Patients in Group B were administered sciatic and femoral blocks using a dual method with ultrasonography and stimulation (25-G Braun needle and Stimuplex HNS 12 stimulator, Melsungen, Germany).

For the sciatic nerve block, $62.5 \mathrm{mg} / 12.5 \mathrm{ml}$ of $0.5 \%$ bupivacaine (Marcaine ${ }^{\circledR} 20 \mathrm{ml}$ flacon, AstraZeneca, Istanbul, Turkey) were mixed with $250 \mathrm{mg} / 12.5 \mathrm{ml}$ of $2 \%$ prilocaine (Citanest 20 $\mathrm{ml}$ flacon, AstraZeneca, Istanbul, Turkey). For the femoral nerve block, $37.5 \mathrm{mg}$ of $0.5 \%$ bupivacaine $(7.5 \mathrm{ml})$ were added to 150 mg of $2 \%$ prilocaine $(7.5 \mathrm{ml})$. The blocks were administered using different syringes under aseptic conditions. All patients received the same volume of local anesthetics: $20 \mathrm{ml}$ of $0.5 \%$ bupivacaine and $20 \mathrm{ml}$ of $2 \%$ prilocaine. Spinal anesthesia was attained with $20 \mathrm{mg} / 4 \mathrm{ml}$ of $0.5 \%$ bupivacaine (Marcaine ${ }^{\circledR} 20$ $\mathrm{ml}$ flacon, AstraZeneca, Istanbul, Turkey) injected aseptically using a $22 \mathrm{G}$ needle (Egemen International, İzmir, Turkey) in the subarachnoid space at the L4-5 levels. Before making the surgical incision, the anesthesia block level was evaluated using pinprick testing at the level of the inguinal ligament and motor block at the knee joint. Sedoanalgesia was given with $1 \mathrm{mg}$ doses of midazolam (Demizolam $5 \mathrm{mg}$ ampule, Dem Ilac. Istanbul, Turkey), $50 \mu \mathrm{g}$ fentanyl (Talinat $0.5 \mathrm{mg} / 10 \mathrm{ml}$ ampule, Ven Ilac., Turkey), and 10-15 mg ketamine (Ketalar 500 mg flacon, Pfizer Ilac., Istanbul, Turkey), if needed. We used midazolam firstly for tactile discomfort during the early stage of the surgery at incremental doses with $1 \mathrm{mg}$. To attenuate tourniquet pain, $50 \mu \mathrm{g}$ fentanyl and $5 \mathrm{mg}$ ketamine were available to be administered alternatively as needed. For hypertensive episodes in which the systolic pressure increased to $180 \mathrm{mmHg}$, we prepared a $50 \mu \mathrm{g}$ glyceryl trinitrate (Perlinganit $10 \mathrm{mg} / 10 \mathrm{ml}$ ampule, Adeka Ilac, Istanbul, Turkey) bolus for the first $10 \mathrm{~min}$ and as a $50 \mu \mathrm{g} / \mathrm{kg} /$ min infusion if it persisted. To treat hypotension (defined as a systolic blood pressure less than $95 \mathrm{mmHg}$ ), we planned to infuse $250 \mathrm{ml}$ of crystalloid and administer $5 \mathrm{mg}$ of ephedrine hydrochloride (Efedrin Hidroklorur $0.05 \mathrm{gr} / 1 \mathrm{ml}$, Osel Ilac, Istanbul, Turkey). For vomiting or intolerable nausea, $10 \mathrm{mg}$ IV metoclopramide (Metpamid $10 \mathrm{mg} / \mathrm{ml}$ ampule, Sifar Ilac, Istanbul, Turkey) was given. In addition to demographic data, the systolic, diastolic, and mean arterial pressures (MAP), $\mathrm{SpO}_{2}$, respiratory rate, and heart rate $(\mathrm{HR})$ were monitored when the patients were taken to the operating room and intraoperatively. During the operation and in the first postoperative hour, pain was recorded on a numeric scale from 0 ("no pain") to 10 ("insufferable pain," $\mathrm{NRS}_{11}$ ) and the Ramsay sedation score was recorded. This score is defined as " 1 " for anxious, restless or both; " 2 " for cooperative, orientated, and tranquil; " 3 ” for responding to commands; " 4 " for brisk response to stimulus; " 5 " for a sluggish response to stimulus; and " 6 " for no response to stimulus. Patient satisfaction was scored as 3, "perfect"; 2, "minor problems not requiring sedoanalgesia"; 1 , "need for sedoanalgesia"; and 0 , "insufferable pain, general anesthesia required." Surgical 
satisfaction was scored as 2, "satisfactory"; 1, "acceptable"; and 0: "not acceptable." The presence of side effects, additional drug requirements, and the presence or absence of nausea and vomiting were also recorded.

The Mann-Whitney U-test was used to compare MAP, $\mathrm{SpO}_{2}$, $\mathrm{HR}$, surgical and patient satisfaction, Ramsay sedation scale values, and the $\mathrm{NRS}_{11}$ data. The Pearson chi-square and Fisher's exact tests were used to compare the rates of nausea and vomiting. $\mathrm{P}$ values $<0.05$ were deemed to indicate statistical significance. The Statistical Package for the Social Sciences (SPSS) ver. 17.0 was used for statistical analyses.

In this study, patient satisfaction determined the effectiveness of the blocks performed. Since we could not estimate the number of patients we might treat with the regional technique during a limited time, we decided to stop collecting patients when the power of the study reached a level greater than 0.95 on post hoc analysis.

\section{Results}

The operations were completed successfully without complications in either group. Three patients in the peripheral nerve block group were excluded from the evaluation due to block failure. There were no differences in demographics between the groups, as shown in Table 1. All patients were female, except for two males in the block group. As shown in Fig. 1, the MAP values in the spinal anesthesia group were significantly lower.

The oxygen saturation differed significantly between the groups from 20 to $100 \mathrm{~min}$. The $\mathrm{SpO}_{2}$ tended to be lower in Group B, as shown in Fig. 2. The incidence of a "state of sleep" in terms of the Ramsay sedation score differed significantly at

Table 1. Demographic and Clinical Data*

\begin{tabular}{lccc}
\hline & Block $(\mathrm{n}=12)$ & Spinal $(\mathrm{n}=15)$ & $\mathrm{P}$ \\
\hline Weight $(\mathrm{kg})$ & $78.8 \pm 11$ & $75.2 \pm 14$ & 0.456 \\
Age (yr) & $69.1 \pm 9$ & $66.7 \pm 9$ & 0.486 \\
Intro MAP & $105.5 \pm 13$ & $95.5 \pm 16$ & 0.167 \\
Pulse (beats/min) & $74.2 \pm 7$ & $80.0 \pm 14$ & 0.277 \\
Saturation & $95.9 \pm 3$ & $96.9 \pm 2$ & 0.456 \\
ASA $^{+}$ & 2 & 2 & \\
Duration (min) & $103.8 \pm 17$ & $99.7 \pm 13$ & 0.373 \\
\hline
\end{tabular}

*Values are expressed as means $\pm \mathrm{SD}$ (means $\pm \mathrm{SD}$ ). ${ }^{\dagger}$ The ASA class value is shown as the mode. MAP: mean arterial pressure. ASA: American Society of Anesthesiologists.
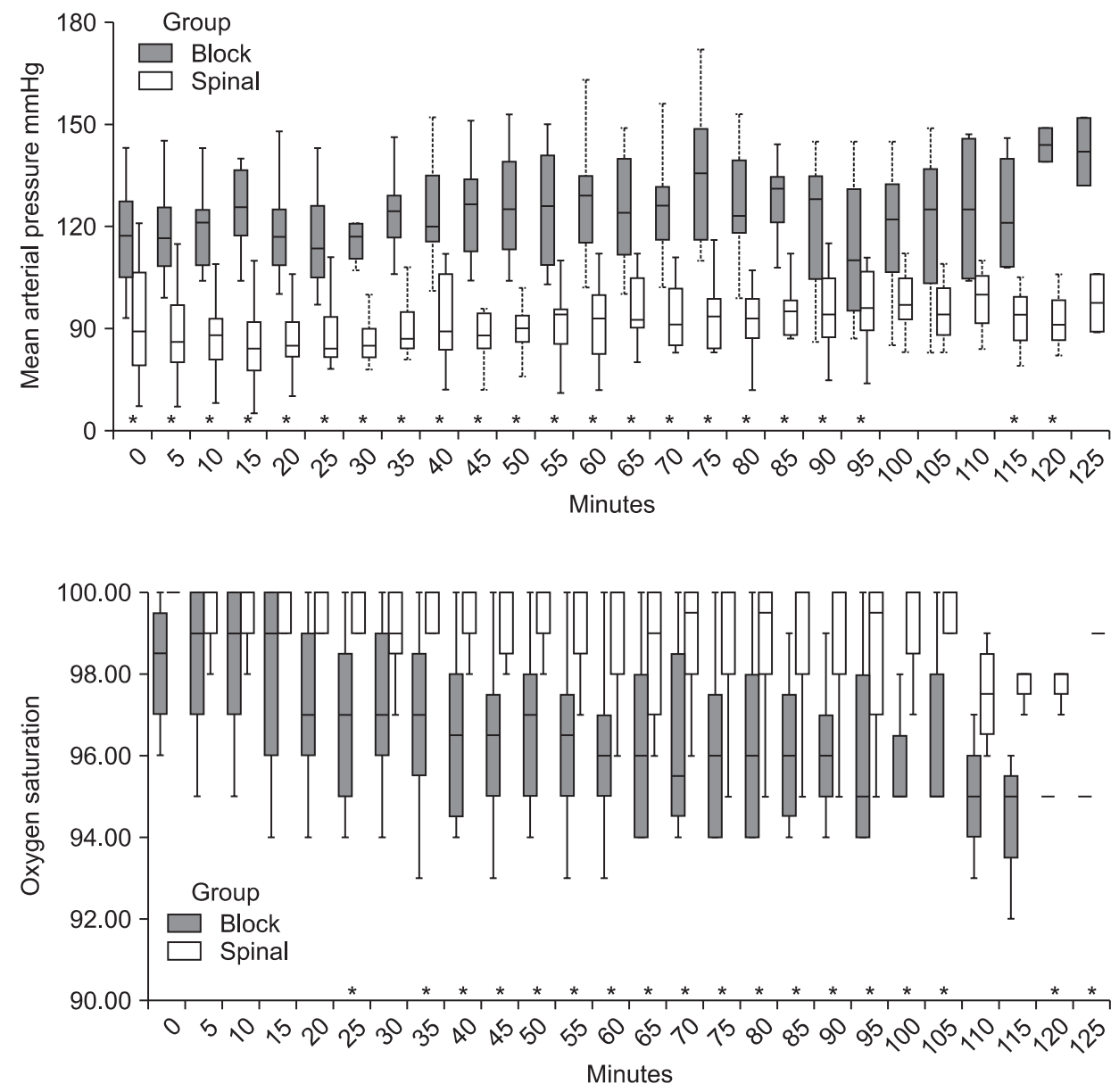

Fig. 1. Difference in the mean arterial pressure between the groups. The statistically significant points are indicated by asterisks $(\mathrm{P}<0.05)$.
Fig. 2. The $\mathrm{SpO}_{2}$ differed significantly between the groups from 20 to $125 \mathrm{~min}$. The statistically significant points are indicated by asterisks $(\mathrm{P}<0.05)$. 
$40,45,50$, and $60 \min (\mathrm{P}=0.01)$. The $\mathrm{NRS}_{11}$ values also differed significantly between the groups at $15 \mathrm{~min}$ and between 70 and $95 \min (\mathrm{P}<0.05)$.

The incidence of nausea was significantly higher in Group S at $110,115,120$, and $125 \mathrm{~min}(\mathrm{P}=0.017,0.006,0.017$, and 0.017 , respectively). No vomiting was observed in any patient. One patient in the block group required $10 \mathrm{mg}$ of IV metoclopramide. No differences in the respiratory and heart rates were identified. Although there was no difference in terms of surgical satisfaction, patient satisfaction differed significantly at $75,80,85,90$, and $105 \min (\mathrm{P}=0.031,0.06,0.06,0.015$, and 0.032 , respectively). The overall median patient satisfaction values in Group $S$ and Group B were 3 and 2, respectively. When patient satisfaction decreased during the operation, midazolam, fentanyl, and ketamine were administered as additional sedatives. Medication was used for each group as follows: block $\pm \mathrm{SD} /$ spinal $\pm \mathrm{SD}$ / $\mathrm{P}$ value, ketamine $8.1 \pm 10 \mathrm{mg} / 0 \mathrm{mg} / \mathrm{P}=0.00$; midazolam $0.8 \pm$ $0.9 \mathrm{mg} / 0.2 \pm 0.8 \mathrm{mg} / \mathrm{P}=0.02$; Fentanyl $37.5 \pm 37 \mu \mathrm{g} / 3.1 \pm 12.5 \mu \mathrm{g} /$ $\mathrm{P}=0.00$. Medication use was significantly more common in Group B. No cardiac arrest, collapse, total spinal block, or lifethreatening arrhythmia was experienced during the operations, and no other serious side effects were observed. Postoperatively, the difference in MAP between the two groups persisted. No postoperative difference in any parameter, including $\mathrm{NRS}_{11}$, was observed.

Post hoc analysis for the power of the study was performed based on patient satisfaction. For power analysis, we used the G*power software (v3.1.5 Franz Faul, Universitat Kiel, Germany) to determine mean values and their standard deviations for all measurements. The overall means and standard deviations for the spinal and block groups were $3 \pm 0.001$ and $2.5 \pm$ 0.56 , respectively. The settings used in the $\mathrm{G}^{*}$ power software are shown in Table 2, and the power of the study was estimated as 0.953 .

Table 2. Power Estimation Parameters in the G*Power Software

\begin{tabular}{llll}
\hline Analysis & \multicolumn{2}{c}{ Post hoc: Computed achieved power } \\
\hline \multirow{2}{*}{ Input } & Tail(s) & $=$ One \\
& Parent distribution & $=$ & Logistic \\
& Effect size $d^{*}$ & $=$ & 1.26 \\
& a error of probability & $=$ & 0.05 \\
& Sample size group 1 & $=12$ \\
& Sample size group 2 & $=$ & 15 \\
Output & Noncentrality parameter $\delta$ & $=$ & $=1.70$ \\
& Critical t & $=$ & $\mathbf{0 . 9 5 3}$
\end{tabular}

*Effect size d computed by the software using the groups' means and standard deviations (Group 1: $2.5 \pm 0.56$ and Group 2: $3 \pm 0.001$ ).

\section{Discussion}

Both surgical and patient satisfaction rates were acceptable in our study. As an effect of sedoanalgesia, a low oxygen saturation began at $20 \mathrm{~min}$ in the block group and increased continuously. As the lowest $\mathrm{SpO}_{2}$ was $92 \%$, the decrease was not important clinically according to the average age of 69 years. The strength of this study was decreased by the fact that blood anesthetic levels were not measured.

We aimed to minimize the local anesthetic dose by using USG during block application; increasing the success rate with USG was not our aim. In addition, we used two major lower extremity blocks instead of four block combinations; we chose not to add lateral femoral cutaneous nerve and obturator nerve blocks to the study to lower the risk of local anesthetic toxicity. For the same purpose, we avoided the three-in-one block. Required doses for surgical anesthesia were greater than the analgesic doses. Wedel and Horlocker [11] recommends a volume of 20-30 $\mathrm{ml}$ for a sciatic nerve block and $20-40 \mathrm{ml}$ for the femoral nerve. Hadzic [12] suggests $15-20 \mathrm{ml}$ for the sciatic nerve and $10-20 \mathrm{ml}$ for the femoral nerve when USG is used during peripheral nerve blocks. We used $25 \mathrm{ml}$ for the sciatic nerve, which is $5 \mathrm{ml}$ more than the dose suggested by Hadzic, and $15 \mathrm{ml}$ for the femoral nerve. While calculating the dose, we did not foresee that the average TKA operation duration would be less than $105 \mathrm{~min}$ and chose the $25 \mathrm{ml}$ dose due to its longer duration of effect. Nevertheless, some may feel that the dose used was too high. Additional studies are needed to determine the optimal dose of local anesthetic for use with USG for surgical anesthesia prior to TKA.

Few studies present peripheral block anesthesia techniques for the lower extremity as an alternative to regional or general anesthesia, and most are case reports [13,14]. However, many articles have compared the effectiveness of various analgesics [15].

In our study, the rate of successful TKA with the peripheral nerve block was $80 \%(12 / 15)$. This percentage does not suggest the routine use of a combined sciatic/femoral block for TKA. However, it should be attempted in select cases in the presence of increased risk factors for general or regional anesthesia. Sansone et al. [16] used sciatic and femoral nerve blocks in 601 arthroscopy patients, only 4 of whom ultimately required general anesthesia. To avoid side effects, such as headache, cardiovascular instability, infection, and urinary retention, spinal anesthesia was not recommended as the first choice in ambulatory arthroscopy.

Kim et al. [17] compared sciatic, femoral, and lateral cutaneous nerve blocks with combined spinal epidural anesthesia for TKA in terms of intraoperative surgical and patient satisfaction and postoperative analgesia in 84 patients. Ultrasonography was not used. Kim et al. found that the level of surgical satisfac- 
tion was higher in their block group. However, we had different results; although the demographic data were similar in both studies, there were significant differences in the duration of surgery at 99.7 and $103.7 \mathrm{~min}$ in our spinal and block groups, respectively, versus 124.5 and $135 \mathrm{~min}$ in the study by Kim et al. This difference may have arisen from the speed of surgery and the need for muscle relaxation. The decrease in muscle tone was greater with spinal anesthesia. In both studies, significantly more sedoanalgesia was used in the block group. While the incidence of nausea was greater in our spinal group, this parameter was not reported by Kim et al.

Spasiano et al. [18] compared spinal anesthesia with sciatic and femoral blocks in 32 arthroscopy patients. The femoral nerve block combination was described as a good alternative to spinal anesthesia as it reduced the incidence of headache, urinary retention, and spinal hematoma. The heart rate in their block group was significantly higher, while we found no difference in heart rate between our two groups. Although Spasiano et al. reported no increase in pain scores due to tourniquet pain in both groups, in the block group, we noticed a difference in the $\mathrm{NRS}_{11}$ score that started at $65 \mathrm{~min}$ and remained significant until 90 min before decreasing and disappearing during the postoperative period. We interpreted this "pain score" difference as a result of tourniquet pain arising from the lateral femoral cutaneous (LFC) nerve. This effect disappeared at the end of the operation on release of the tourniquet.

The most difficult aspect of using peripheral blocks for TKA is potential local anesthetic toxicity due to the quantity of nerves that innervate the area and the volume of local anesthetic required. The sciatic, femoral, LFC, and obturator nerves all have branches that supply the knee area [19]. Bupivacaine can cause convulsions as the plasma level approaches $4 \mu \mathrm{g} / \mathrm{ml}$, which can occur when $80 \mathrm{ml}$ (or $400 \mathrm{mg}$ ) are administered to block the sciatic, femoral, and lateral cutaneous nerves [20].

The femoral nerve innervates most of the knee joint, and the sciatic nerve supplies the posterior aspect of the joint. The course of the obturator nerve is variable, but it can innervate the joint via a few small branches [21], innervating the skin of the medial knee and a small medial area of bone that is close to the joint. The area innervated by the obturator nerve are affected during a very short period of the procedure and can be managed with sedoanalgesia. The LFC nerve transmits the pain caused by the concomitant tourniquet rather than the surgical nociception [22]. Transmission by the LFC nerve increases mostly when the tourniquet pain increases, usually near the end of the operation. This decreases patient satisfaction, which can be managed with sedoanalgesia.

A study by Jacob et al. [23] that included 13,329 patients undergoing TKA at the Mayo Clinic between 1988 and 2007 found that the incidence of peripheral nerve injury was $0.79 \%$. These injuries were related to tourniquet application duration and patient age. The control of tourniquet pain with sedoanalgesia is preferred to anesthesia methods that increase the injury risk by using blocks with a longer duration. Saricaoglu et al. [24] found that the use of ketamine and sedoanalgesia with a tourniquet for arthroscopy decreased the malonyl dialdehyde and hypoxanthine levels, which are related to ischemia/reperfusion injury. By maintaining the local anesthetic dose at a low level using only sciatic and femoral blocks in high-risk patients during general and regional anesthesia, TKA is possible with the aid of USG. Whenever the surgery may also affect tissues supplied by the obturator and lateral femoral cutaneous nerves, minimum doses of sedatives and analgesics should be used. Future studies should examine the role of double, triple, and even quadruple ultrasound-guided nerve blocks for TKA using small doses while monitoring blood levels of local anesthetic.

In conclusion, we believe that ultrasound-guided sciatic and femoral blocks with sedoanalgesia are suitable alternative methods for unilateral TKA in patients in whom regional anesthesia may be difficult and general anesthesia may be too risky; moreover, surgical satisfaction can be achieved during unilateral TKA.

\section{Acknowledgments}

We present specials thanks to Dr. Hikmet Tekce for his great contribution.

\section{References}

1. Singh JA. Epidemiology of knee and hip arthroplasty: a systematic review. Open Orthop J 2011; 5: 80-5.

2. Namba RS, Paxton L, Fithian DC, Stone ML. Obesity and perioperative morbidity in total hip and total knee arthroplasty patients. J Arthroplasty 2005; 20(7 Suppl 3): 46-50.

3. Jeon YT. Peripheral nerve block for anesthesia in patients having knee arthroplasty. Korean J Anesthesiol 2012; 62: 403-4.

4. Enneking FK, Chan V, Greger J, Hadzic A, Lang SA, Horlocker TT. Lower-extremity peripheral nerve blockade: essentials of our current understanding. Reg Anesth Pain Med 2005; 30: 4-35.

5. Murray JM, Derbyshire S, Shields MO. Lower limb blocks. Anaesthesia 2010; 65 Suppl 1: 57-66.

6. Koscielniak-Nielsen ZJ, Dahl JB. Ultrasound-guided peripheral nerve blockade of the upper extremity. Curr Opin Anaesthesiol 2012; 25: 253-9. 
7. Sripada R, Reyes JJ, Sun R. Peripheral nerve blocks for intraoperative management in patients with hemophilia A. J Clin Anesth 2009; 21: 120-3.

8. Touray ST, de Leeuw MA, Zuurmond WW, Perez RS. Psoas compartment block for lower extremity surgery: a meta-analysis. Br J Anaesth 2008; 101: 750-60.

9. Adalı S, Erkalp K, Erden V, Cömlekçi M, Bülbül M, Aldemir T. Spinal anesthesia and combined sciatic nerve/lumbar plexus block techniques in lower extremity orthopedic surgery. Acta Orthop Traumatol Turc 2011; 45: 225-32.

10. Ozhan M, Orhan E, Kurklu M, Demirap B, Suzer A, Cekmen N, et al. Comparison of peripheral nerve blocks, spinal anesthesia and general anesthesia for ambulatory surgery of the lower limb. Nobel Medicus 2012; 8: 73-80.

11. Wedel DJ, Horlocker TT. Nerve Blocks. In: Miller's anesthesia. 7th ed. Edited by Miller RD: Philadelphia, Churchill Livingstone-Elsevier. 2010, pp 1652-9.

12. Hadzic A. Nerve Stimulator and Surface based Nerve Block Techniques. In: Hadzic's peripheral nerve blocks and anatomy for ultrasoundguided regional anesthesia, 2nd ed. New York, McGraw-Hill Professional. 2012, pp 229-72.

13. Kocum A, Turkoz A, Bozdogan N, Caliskan E, Eker EH, Arslan G. Femoral and sciatic nerve block with $0.25 \%$ bupivacaine for surgical management of diabetic foot syndrome: an anesthetic technique for high-risk patients with diabetic nephropathy. J Clin Anesth 2010; 22: 363-6.

14. Marhofer P, Schrogendorfer K, Andel H, Koinig H, Girsch W, Kapral S, et al. Combined sciatic nerve-3 in 1 block in high risk patient. Anasthesiol Intensivmed Notfallmed Schmerzther 1998; 33: 399-401.

15. Fowler SJ, Symons J, Sabato S, Myles PS. Epidural analgesia compared with peripheral nerve blockade after major knee surgery: a systematic review and meta-analysis of randomized trials. Br J Anaesth 2008; 100: 154-64.

16. Sansone V, De Ponti A, Fanelli G, Agostoni M. Combined sciatic and femoral nerve block for knee arthroscopy: 4 years' experience. Arch Orthop Trauma Surg 1999; 119: 163-7.

17. Kim JH, Cho MR, Kim SO, Kim JE, Lee DK, Roh WS. A comparison of femoral/sciatic nerve block with lateral femoral cutaneous nerve block and combined spinal epidural anesthesia for total knee replacement arthroplasty. Korean J Anesthesiol 2012; 62: 448-53.

18. Spasiano A, Flore I, Pesamosca A, Della Rocca G. Comparison between spinal anaesthesia and sciatic-femoral block for arthroscopic knee surgery. Minerva Anestesiol 2007; 73: 13-21.

19. McNamee DA, Parks L, Milligan KR. Post-operative analgesia following total knee replacement: an evaluation of the addition of an obturator nerve block to combined femoral and sciatic nerve block. Acta Anaesthesiol Scand 2002; 46: 95-9.

20. Moore DC, Mather LE, Bridenbaugh LD, Balfour RI, Lysons DF, Horton WG. Arterial and venous plasma levels of bupivacaine following peripheral nerve blocks. Anesth Analg 1976; 55: 763-8

21. Neal JM. Assessment of lower extremity nerve block: reprise of the Four P's acronym. Reg Anesth Pain Med 2002; 27: 618-20.

22. Morin AM, Pandurovic M, Eberhart LH, Wagner S, Kunz C, Nussle W, et al. Is a blockade of the lateral cutaneous nerve of the thigh an alternative to the classical femoral nerve blockade for knee joint arthroscopy? A randomised controlled study. Anaesthesist 2005; 54: $991-9$.

23. Jacob AK, Mantilla CB, Sviggum HP, Schroeder DR, Pagnano MW, Hebl JR. Perioperative nerve injury after total knee arthroplasty: regional anesthesia risk during a 20-year cohort study. Anesthesiology 2011; 114: 311-7.

24. Saricaoglu F, Dal D, Salman AE, Doral MN, Kilinc K, Aypar U. Ketamine sedation during spinal anesthesia for arthroscopic knee surgery reduced the ischemia-reperfusion injury markers. Anesth Analg 2005; 101: 904-9. 